\title{
KÜLTÜR COĞRAFYASI AÇISINDAN VEZİRKÖPRÜ YÖRESINNDE DOKUMA KÜLTÜRÜ
}

\author{
THE WEAVING CULTURE IN VEZIRKOPRU REGION IN \\ TERMS OF THE CULTURAL GEOGRAPHY
}

\section{УСЛОВИЯХ КУЛЬТУРНОЙ ГЕОГРАФИИ КУЛЬТУРЫ ВЕЗИРКЁПРИ В ТКАЦКИЙ}

\section{Seyfullah GÜL ${ }^{* *}$}

Öz

Dokumacıllk, toplumların yaşam biçimlerini, sosyo-ekonomik yapılarını, davranıș biçimlerini ve yerel kimliklerini güçlü bir şekilde yansıtan kültürel miras değerleridir. Bu kültür ürününün mekânsal dağıllşı ve mekânsal çeşitliği büyük ölçüde tarihi yapı, çevre, kültür ve dağılış ilişkileri açısından yöreden yöreye farklılık göstermektedir.

Makalede Vezirköprü yöresindeki dokuma kültürünün ortaya çıkışı ve gelişimi kültür coğrafyası açısından tartışılmıştır. Çalışma ile yöredeki dokuma kültürünün tarihi yapısı, dokuma kültürüne ait özelliklerin ortaya konulması ve yöreye ait bir dokuma envanteri oluşturularak bu kültürel mirasın korunmasına katkı sağlanması amaçlanmaktadır. Ayrıca yöredeki dokuma kültürünün oluşması ve şekillenmesinde etkili olan coğrafi çevre bileşenleri ortaya konularak dokuma kültürünün yöre içindeki mekânsal dağılışı ve mekânsal çeşitliliklerinin tasvir edilmesi de amaçlanmaktadır.

Vezirköprü yöresinin dokuma kültürü potansiyelini ve özelliklerini ortaya koymak ve dikkatleri yöreye çekmeye yardımcı olmaya odaklanan bu araştırmada; literatür taraması, kaynak kişi görüşmeleri, sahadaki inceleme ve gözlemlerin sonuçlarından yararlanılmıştır.

Dokumacılık, Vezirköprü'de Demir Çağı'ndan günümü yüz yıllardır varlığını koruyan kültürel bir mirastır. Yörede dokuma ürünlerinde kullanılan hammadde, dokuma ürünlerinin boyutu, biçimi ve üzerlerindeki desenler birbirinden farklıdır. Yöredeki dokuma kültürü; Susuz Bezi dokumacıllğı, Soruh Vadisi kilim, heybe, çorap ve boncuklu taç dokumacılığı ve Özyörük Köyü yörük dokumaları ile kilim (çöpür) ve çuval dokumacilığı olmak üzere üç gruba ayrılır. Bu farklılıkta yöredeki dokuma kültürünün Demir Çă̆ı'na kadar tarihlendirilmesi yanında yörenin tarih boyunca farklı kültürlere (Hitit, Frig, Roma, Bizans, Türk) ev sahipliği yapması ve yörenin coğrafi çevre bileşenleri de etkilidir.

Anahtar Kelimeler: Kültür, Kültürel Miras, Dokumacılık, Vezirköprü, Kültür Coğrafyası

\footnotetext{
*Bu makale, "Vezirköprü Yöresinde Kültür Turizmi" adlı doktora tezinden üretilmiştir. ** Dr. Öğr. Üyesi, OMÜ Turizm Fakültesi, Turizm Rehberliği Bölümü, seyfullah.gul@omu.edu.tr

DOI: 10.17498/kdeniz.411145
} 


\begin{abstract}
Weavings are cultural heritage values that strongly reflect the lifestyles, socioeconomic structures, patterns of behaviour and local identities of societies. The spatial distribution and the spatial variety of this cultural product vary greatly from region to regional the standpoint of historical structure, environment, culture and distribution relations.In the article, the emergence and development of the weaving culture in the Vezirköprü region in terms of cultural geography is discussed. The aim of this study is to contribute to the preservation of this cultural heritage by establishing the historical structure of the weaving cultures in the region, revealing the characteristics of the weaving culture and creating a weaving inventory belonging to the region. It is also aimed to describe the spatial distribution and spatial diversity of the weaving culture in the region by introducing the geographical environmental components which are effective in the formation and embodiment of the weaving cultures in the region.

In this research which focuses on revealing the potential and characteristics of weaving culture of Vezirköprü region and helping to attract attention to the region, the results of literature review, source interviews, field reviews and observation are used.

Weaving in Vezirköprü is a cultural heritage that preserves its existence for hundreds of years since Iron Age. The raw materials used in the woven products in the region, the size, shape and patterns of the woven products are different from each other. Weaving culture in the region divided into three groups: (a) Susuz Bezi weaving, (b) Soruh Valley rug, saddlebag, sock and beaded crown weaving and, (c) Özyörük Village nomad weaving, rubbing rugs and sack weaving. The difference is due to the fact that the weaving cultures on the site are dated to the Iron Age, region is hosted by different cultures (Hittite, Phrygian, Roman, Byzantine, Turkish) throughout history and the geographical environment components.
\end{abstract}

Key Words: Culture, Cultural Heritage,Weaving, Vezirkopru, Cultural Geography.

\title{
АННОТАЦИЯ
}

Ткачество - это ценность культурного наследия, которая сильно отражает образ жизни, социально-экономические структуры, модели поведения и местные идентичности обществ. Пространственное распределение этого культурного продукта и пространственное разнообразие сильно различаются с точки зрения исторической структуры, среды, культуры и распределения.

Появление и развитие ткацких культур в регионе стати Везиркупри обсуждалось с точки зрения культурной географии. Целью этого иследования является содействие сохранению этого культурного наследия путем установления исторической структуры ткацких культур в регионе, выявления особенностей культуры ткачества и создания ткацкого инвентаря, принадлежащего региону. Он также предназначен для описания пространственного распределения и пространственного разнообразия культуры ткачества в регионе путем введения географических компонентов окружающей среды, которые эффективны в образовании и формировании ткацких культур в регионе.

Ткачество моего дня из железного века в лице Везиркёпри является культурным наследием, которое защищает свое существование в течение многих лет.

Сырье, используемое в тканых изделиях в регионе, размер, форма и структура тканых изделий отличаются друг от друга. Ткацкая культура в регионе разделены на три группы: нетканое плетение, ковер долины Сорук, седельная сумка, носок и 
вышитый бисером коронное ткачество, а также кочевое плетение Езйюрек деревни и ткачество ковра и мешков. В этом различии ткацкие культуры региона приурочены к железному веку, и на регион также влияют различные культуры (Хеттский, Фригийский, Римский, Византийский, Турецкий) на протяжении всей истории и компонентов географической среде.

Ключавые слова: Култура, Култура истории, Ткачество, Везиркёпри, Культурной Географии.

\section{Giriș}

Kırsal alanlar; yerel yaşam biçimleri ve özgünlükleri ile birçok kültürel değerin gelișip șekillendiği önemli kültür ocaklarıdır. Yerel kültürü oluşturan değerlerin çoğu kırsal alanlardaki bu ocaktan çıkar ve yayılır. Bu kültürel değerler ise büyük ölçüde ortaya çıktığ ve geliştiği yörenin coğrafi çevre bileşenlerine göre şekillenmektedir. Bu etkiyi Türkiye'nin coğrafi çevre bileşenlerinin kısa mesafelerde farklılaşması ve değişiminin sahip olduğu somut olan ve somut olmayan kültürel değerlerin çeşitlenmesinde ve dağılıșında görmek mümkündür. Hiç şüphesiz kültür, coğrafi çevre bileşenlerinden etkilendiği kadar ortaya çıktığı ve geliştiği coğrafyayı da etkilemektedir. Zira toplumlar kültürüyle, kendini kuşatan ve kucaklayan coğrafyasına bir başka görünüm kazandırır. Hatta doğal çevre üzerine kültür yoluyla serpilen farklı kültürel değerler, o coğrafyayı o kültüre tapular, adeta mal eder.

Bir toplumun tarihsel süreç içinde ürettiği ve kuşaktan kuşağa aktardığı her türlü maddi ve manevi özelliklerin bütünü olan kültür, o toplumun kimliğini oluşturur ve onu diğer toplumlardan ayırır. Toplumları birbirinden ayıran kültürel değerler içerisinde ise el sanatları; ortaya çıkış süreçleri, gelişimi, değişimi ve dağılışları ile önemli bir yere sahiptir. Çevre şartlarına göre değişim gösteren ve daha çok yerellik taşıyan el sanatları; toplum yapısının şartları içinde oluşmuş, kısa mesafelerde değişim gösteren, sosyal açıdan ise daha çok sembolik karakter taşıyan özelliklere sahiptir (Oğuz, 2000, s. 22). Etnografik değeri olması yanında sanat öğeleri de tașıyan bu el sanatı unsurları, zamanla halk tarafından kullanılmaları, alınıp satılmaları, gelir getirmeleriyle kültürel özellik taşıyan ürünlere dönüşebilmektedirler (Omur, 1997, s. 471).

Türk el sanatları içerisinde el dokumaları, Türk kültürel kimliğinin oluşmasında önemli yeri olan kültür öğeleridir. Orta Asya'dan Anadolu'ya uzanan tarihi seyirde sanatkârının sadece düğüm atarak dokuma oluşturmadığı, dokuduklarına kültürü ve inanç sistemiyle beraber yüreğini de eklediği, desenlerinde ikonografik manalarla dolu mesajlar aktardığı bilinmektedir (Aytaç, 2008, s. 203-220). El dokumaları, sahip olduğu kültürün geleneksel özellikleri yanında ortaya çıktığı ya da taşındığı coğrafyayı da büyük ölçüde yansıtır. Zira dokumaları oluşturan hammaddelerde, dokumacılıkta kullanılan araç gereçlerde ve dokuma ürünlerine işlenen motiflerde kültür kodları yanında yaşadığı coğrafyaya ait özellikleri de görmek mümkündür. Yani dokumaların üretiminden tüketimine bütün aşamalarında coğrafi çevre ile uyum vardır (Karabaşa, 2013).

Tarihi kaynaklar ve alan araştırmaları, Vezirköprü şehri ve yakın çevresinde çam ağacından "boduç" (tahta su kabı) yapıldığını, yöre halkının çöğür, tanbura, rüze, şarkı, yunka adlı sazları yaparak para kazandıklarını (Çelebi, 1986, s. 690), bakır ve kalaycılık, demircilik, semercilik, saraçlık (koşum takımı yapımı vs), nalburculuk, sepet ve süpürgecilik, ağaç işleri, kilim ve bez dokumacılığı, kunduracılık, değirmencilik, semavercilik gibi günümüze ulaşabilmiş geleneksel el sanatları yanında debbağcılık, tuğlacılık, kiremitçilik, çanak-çömlek yapımı ve daha sayamadığımız birçok el sanatının günümüze ulaşamayan el sanatlarının varlına işaret etmektedir. 
Vezirköprü yöresi, Türk kültürel kimliği yanında yerel coğrafi çevre özelliklerini de yansıtan kilim, boncuklu taç, bez bebek, heybe, çorap, kuşak, kolon, çöpür kilim ve bez dokuma gibi renk ve desen özellikleri itibarıyla kendine özgü karakteristiği olan zengin bir dokuma kültürü mirasına sahiptir. Bu mirasın bir bölümü hızla gelişen teknolojiye ayak uyduramayarak unutulmuş ise de bir kısmının geçmişten günümüze üretiliyor ve yaşatılıyor olması önemlidir. Hiç şüphesiz dokuma kültüründeki bu sürekliliği Vezirköprü’nün yerleşme tarihinde ve coğrafi özelliklerinde aramak gerekmektedir. Vezirköprü’nün yerleşme tarihi Kalkolitik döneme kadar (M.Ö 5500 - M.Ö 3000) uzanmaktadır (Oymaağaç-Nerik, 2011, s. 20-24). Yörenin sırasıyla Hitit, Frig, Pers, Roma, Bizans dönemlerinde kesintisiz olarak yerleşim yeri özelliğini koruması,1071'de Türklerin Anadolu'ya girişleriyle Türkmen aşiretlerinin bölgeye yerleştirilmeleri, Anadolu Selçuklu Devleti ve Osmanlı Devleti'nin önemli merkezlerinden biri olması dokuma kültürünün gelişiminde etkili olmuştur.

Tarımsal faaliyetler yanında el sanatları gibi kültürel faaliyetlerde büyük ölçüde doğal ve beşeri çevre faktörlerine göre şekillenmektedir. Vezirköprü yöresinin sahip olduğu topografya, iklim, toprak, hidrografya gibi doğal çevre özellikleri ve tarihi yapısı geçmişten günümüze bir çok el sanatının icra edildiği önemli alanlardan biri olmasını sağlamıştır. Yöre geçmișten günümüze dokuma kültürüne hammadde sağlayan keten, kenevir, pamuk ve ipekböcekçiliği gibi ekonomik faaliyetlerin yapılabildiği önemli alanlardan biri olmuştur.

Son ylllarda UNESCO, MEB Hayat Boyu Öğrenme Genel Müdürlüğü, Halk Eğitim Merkezleri, Kalkınma Ajansları vb. kuruluşların el sanatlarının araştırılması, gün yüzüne çıkarılması ve yaşatılması yönündeki çabaları, insanların somut olmayan kültürel miras değerlerinin kısmen de olsa farkında olmalarına neden olmuştur. Nitekim Orta Karadeniz Kalkınma Ajansı'nın (OKA), Susuz Bezi ve Sarıdibek-Tahtaköprü kilim dokumacilığının canlandırılmasına yönelik projeleri sayesinde var olan dokuma ustaları belirlenmiş, kurslara alınan yeni kursiyerlerin eğitimi sağlanmış ve çıraklar yetiştirerek bu el sanatlarının kaybolması kısmen de olsa ötelenmiştir.

\section{Amaç, Materyal ve Yöntem}

Dokumacılık kültürünün kültür coğrafyası bakımından incelemeye alınan Vezirköprü yöresi, Orta Karadeniz Bölümü'nde Batı Karadeniz Dağları'nın doğuya doğru uzanan kesiminin Aşağı Kızılırmak Vadisi çevresine rastlayan kıyı ardı kuşağında yer almaktadır. Yöre, İsfendiyar Dağları'nın doğuya doğru uzanan kesiminin güneyinde, Samsun il merkezinin güneybatısında bulunur (Şekil 1).

Kültürü konu edinen disiplinlerden biri de coğrafyadır. Kültür coğrafyası, insanların içinde yaşadıkları fiziki çevreden çok, insanın kültürel çevresini konu alır. Bu nedenle kültür coğrafyası, kültürün ve toplumların mekânsal farklılıkları ile kültürdeki mekânsal çeşitlilikleri tasvir etme ve yorumlamalarıyla diğer disiplinlerden ayrılırlar (Tümertekin ve Özgüç, 2009, s. 96-97).

Araştırmanın ana materyalini Orta Karadeniz Bölümü'nde bulunan Vezirköprü yöresindeki dokuma kültürüne ait kilim, boncuklu taç, bez bebek, heybe, çorap, kuşak, kolon, çöpür kilim ve bez dokuma gibi kültürel miras değerleri oluşturmaktadır. Ayrıca çalışmanın analiz ve değerlendirme aşamalarında kullanılan haritalar, veriler, fotoğraflar ve dokümanlar araştırma materyali olarak değerlendirilmiştir. 


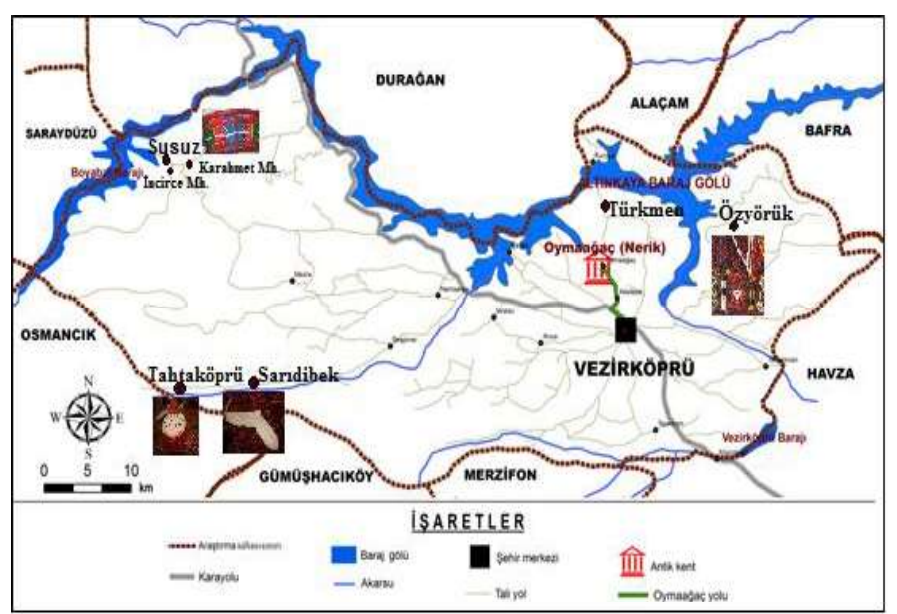

Șekil 1. Vezirköprü yöresinde dokuma kültürü dağılıș haritası.

Vezirköprü yöresinin dokuma kültürü potansiyelini ve özelliklerini ortaya koymak ve dikkatleri yöreye çekmeye yardımcı olmaya odaklanan bu araştırmada; nitel araştırma yöntemi; literatür taraması, kaynak kişi görüşmeleri, sahadaki inceleme ve gözlemlerin sonuçlarından yararlanılmıştır.

\section{Vezirköprü'de Dokuma Kültürü}

Vezirköprü'de yapılan arkeolojik kazı ve yüzey araștırmaları, Vezirköprü yöresinde dokuma külttürünün Tunç Çağı'ndan beri (M.Ö 3000 - 1200) varlığını sürdürdüğünü göstermektedir. Özellikle Adatepe-Tepecik Höyükteki yüzey araştırmalarında ve Oymaağaç Höyük kazısının Frig katmanında tespit edilen çok sayıda tezgâh ağırlığı (ağırşak) ve bunların incelenmesinden elde edilen veriler yörede dokuma kültürünün çağlar öncesindeki varlığına işaret etmektedir (Gül ve Yılmaz, 2015), (Foto 1). Ayrıca Roma döneminde de yörede dokumacılığın hayli saygın bir yeri olduğunu söylemek mümkündür. Zira Vezirköprü yöresindeki bazı Roma dönemi mezar taşlarında yün eğirmede kullanılan kirman ve yün kutusu figürlerinin (Foto 2) bulunuyor olması yine yörede yapılan bir inșaat kazısında Roma dönemine ait bir genç kız mezarındaki bulgular arasında yün eğirme çıkrığına ait iğ demirinin (Foto 3) olması da yörede dokumacıllğa verilen önemin göstergeleridir. Tüm bu bulgular yörede dokumacıllğın tarihinin çağlar öncesine dayandığını, yöre insanının çağlar öncesinde de ailesel ihtiyaçlardan çok daha fazla dokuma ürünü ürettiklerini, üretilen dokuma ürünlerin ticaretinin yapıldığını ve dokumacılığın çağlar boyunca yörenin önemli geçim kaynaklarından biri olduğunu ortaya koymaktadır. Bu görüşü destekler bir şekilde Tunç Çağı boyunca Adatepe ve Oymaağaç köylerinde ören yeri sakinlerinin yoğun bir șekilde dokumacılıkla uğrașmıș oldukları, hatta büyük olasıllkla bir dıș satım gerçekleștirmiș olabilecekleri ileri sürülmektedir (Kıvrak, 2014, s. 467).

El sanatlarının birçoğunun şekillenmesinde büyük oranda ortaya çıktığı coğrafyada yapılan ekonomik faaliyetler etkili olmaktadır. Vezirköprü yöresindeki dokuma kültürü de yörenin coğrafyasında yapılan ekonomik faaliyetlerden en fazla etkilenen kültürel değerlerden biridir. Yapılan yüzey araştırmaları ve Oymaağaç-Nerik kazısında ortaya çıkarılan bulgular, Vezirköprü yöresinde Kalkolitikten günümüze sosyo-ekonomik hayatın kesintisiz devam ettiğine işaret etmektedir. Oymaağaç kazısında bulunan çeşitli dönmelere 
ait çukurlardan alınarak yapılan toprak analizleri, Demir Çağı'nda Vezirköprü yöresinde bol miktarda arpa, buğday, siyez, antik mısır ve çavdar üretildiği ve tüketildiğini göstermektedir. Ayrıca bu analizlerde, Demir Çağı'nda darı, mürdümük, bezelye, burçak, mercimek, üzüm, incir yanında keten bitkisinin tohumlarının bulunması (Oymaağaç Höyük-Nerik Raporu, 2011, s. 23) yörenin, dokumacılık için hammadde oluşturan ürünlerin yetiştirildiği bir bölge olduğunu göstermektedir.
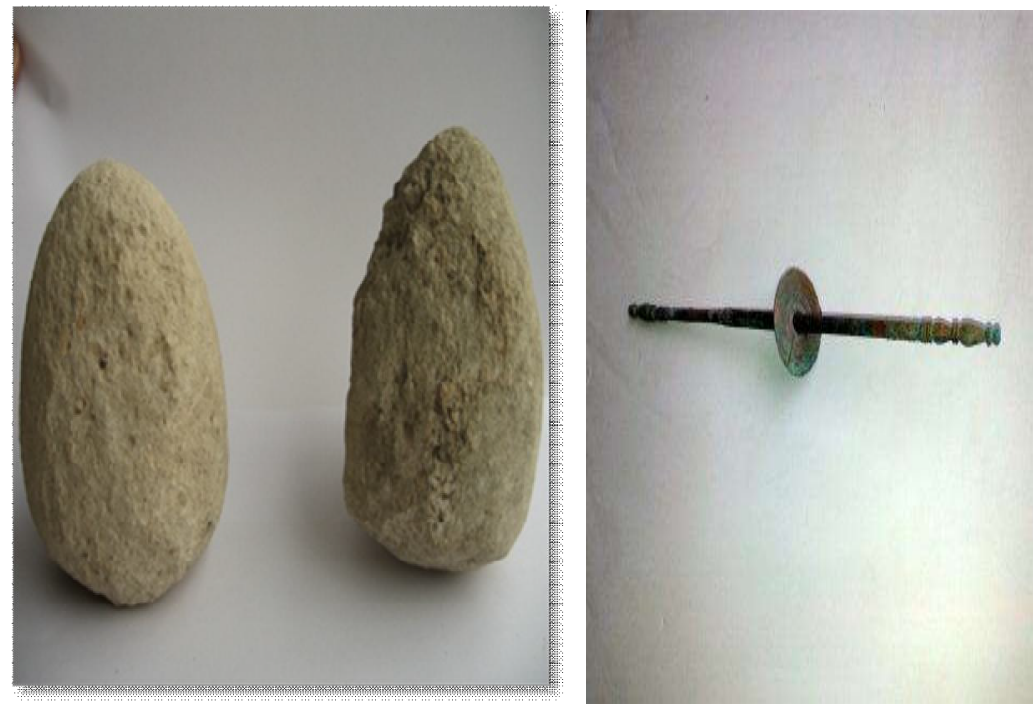

Foto 1. Oymaağaç Höyük kazısının Frig katmanında tespit edilen tezgah ağırlığı (ağırşak) (B.Kıvrak )
Foto 2. Roma dönemine ait bir genç mezarındaki bulgular arasında yün eğirme çıkrığına ait iğ demiri (B.Kıvrak).

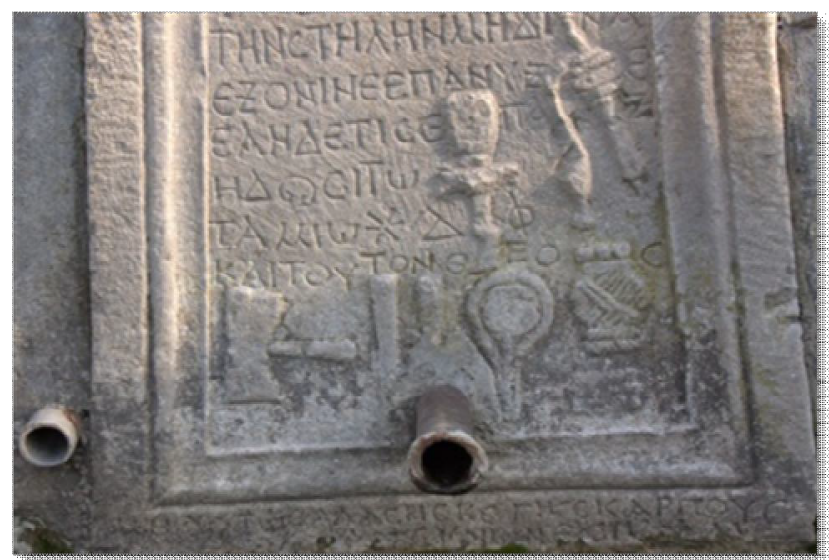

Foto 3. Roma dönemi mezar taşlarında yün eğirmede kullanılan kirman ve yün kutusunun figürleri (B.Kıvrak). 
Dokumacılık, Selçuklu ve Osmanlı döneminde de yörenin önemli ekonomik faaliyetlerinden biri olmaya devam etmiștir. Evliya Çelebi (1986), Vezirköprü’nün önemli bir tarım merkezi olması yanında pamuk bezi ve ipliği ile mavi bezinin meşhur olduğunu belirtmektedir (s. 232). Yine yörede sahtiyan (boyalı bir tür deri ve bundan üretilen eşya), kilim, çul gibi dokuma ürünlerinin üretildiği aktarılmaktadır (Şemsettin Sami,1896).

XIX. yüzyılda Amasya, Vezirköprü ve Tokat, Sivas vilâyetine bağlı olup vilâyetin sahip olduğu 13 bin dolayındaki dokuma tezgâhı Osmanlı Devleti'nin son yıllarına kadar ayakta kalmayı başarabilmiștir. Özellikle XIX. yüzyılın sonlarına doğru Kayserili tüccarlar, Adana'dan getirdikleri Adana pamuğunu Amasya'da ve Vezirköprü'de iplik hâline getirilmekte ve bu ipliklerden kaba basmalar, çadır ve yelken bezleri yapmaktaydılar (Aygün, 2009, s. 41-76).

Sinop Konsolosu Fourcade (1806), Vezirköprü’ye yapmış olduğu geziye dair notları içeren raporunda Vezirköprü'deki dokumacılık ve dokuma ürünleri üzerinde önemle durmakta, Vezirköprü'de pamuklu dokuma ürünleri ve muslinler ${ }^{* * *}$ imal edildiğini aktarmaktadır. Ayrıca Vezirköprü’de üretilen bu ürünler İstanbul, Tokat, Ankara ve İzmir tüccarlarına da satılmaktadır. Vezirköprülü arabacılar bu dört şehre giderek buralardan ipekliler, maroken, ${ }^{* * * *}$ şal ve çivit ${ }^{* * * *}$ alırlard. Amasya ve Kayseri ise bu taraflardan kökboyası sağlamaktadır. Vezirköprülü imalatçılar her sene 50 bin kuruştan daha fazla Kıbrıs ve Kilikya pamuğu kullanmaktadırlar. Bu pamuk aynı zamanda İzmir'den de gelmektedir. Kızılırmak vadisine yayılan bazı Türkmen köyleri pamuk sağlasa da bunun miktarı azdır. Bu pamuktan beyaz, kırmızı ve mavi renkli bir kumaş elde edilir ve şilte* yapılır. Ayrıca çok büyük olmayan havlu da imal edilir. Türkler keten havluları daha beyaz ve daha ucuz olduğu için tercih etmektedir. Konsolos, türban denilen sarık ve tülbent denilen kumaşın başlıca üretim kalemi olduğunu belirtir. Halkın muslinleri kırmızı yün bir takkenin etrafına doladığını ve bu ürünlerin Tunus ve Fransa' dan (Orleans) geldiğini belirtir (Fourcade, 1806; Y1lmaz, 2015, s. 155).

19. yüzyılın başlarında Vezirköprü'de dokuma ürünü muslin, maroken, şal, şilte ile dokumacılıkta kullanılan çivit ve kökboyası gibi ürünlerin ulusal ve uluslararası düzeyde ticaretinin yapılması yörede dokumacılığın ihtiyaçtan çok ticari bir faaliyet olarak yapıldığını ve ilçe ekonomisi için önemini ortaya koymaktadır.

Cumhuriyet döneminde de yöredeki evlerin bir çoğunda "çulfalık" ve "düzen" olarak adlandırılan dokuma tezgâhları ailenin bu alandaki ihtiyacını karşılamasının yanı

*** Muslin düz dokuma bir pamuklu kumaș tipidir. Çok şeffaf ince dokumalardan kaba dokumalara kadar birçok farklı kalınlıkta üretilirler. Genelde düz renktir. Adını ilk üretildiği yer olan Irak'taki Musul şehrinden alır. gelen musuli sözcüğü köken olarak gösterilebilir. Erken dönem muslinler, özellikle Dakka'da (modern Bangladeş), olağanın dışında narinlikte elde eğirilmiş ipliklerle dokunuyordu. 17 ve 18. yüzyıllar boyunca Avrupa'ya sıklıkla bu bölgelerden muslin ihraç edilmekteydi. 2013 yılında, Bangladeş'teki geleneksel Jamdani muslini dokuma sanatı, UNESCO tarafından İnsanlığın Sözlü ve Somut Olmayan Kültürel Mirasının Başyapıtları listesine dahil edilmiştir

(http://www.oed.com/view/Entry/124185).

Maroken: İlk kez Fas'ta, keçi derisinin bitkisel maddelerle sepilenip boyanmasıyla elde edilen, bugün her ülkede yapılan çok yumuşak deri (TDK, 2018).

*Çivit: Eskiden çivitotundan elde edilen, şimdi yapay olarak yapılan, mavi renkli, beyaz çarșaf ve çamașırda olușmuș sarılığı gidermek, onlara mavimtırak bir renk vermek için çamaşırın son suyuna karıştırılan toz boyadır (TDK, 2018).

Şilte: Üstünde oturulan, yatılan, içi yünle, pamukla doldurulmuş döşek (TDK, 2018). 
sıra, satarak geçimini de sağladıkları önemli bir kaynak olmuştur. Özellikle 1970'li yılların ortalarına kadar Vezirköprü'deki bir çok evde "çulfalık" denen tezgâhlarda dokunan dokumaların özellikle Merzifon'dan gelen tüccarlarca evlerden tek tek toplanarak satın alındığı bilinmektedir. Daha çok yatak çarşafı ve göynek olarak adlandırılan içlik giysiler ve don dikimi için üretilen bu dokumalar, ilçenin kendine özgü dokuma tarzını oluşturmuş̧tur. Özellikle köylerde uzun yıllar içerisinde gelenekselleşmiş çoğunlukla boyasız ana zemin üzerine kırmızı şeritlerin kullanıldığı dokumalar, çeyiz sandıklarının da vazgeçilmez unsurlarıydı ve yöre kadınının birçok giysisinde kullanılırdı (Kıvrak, 2014, s. 467).

Ekonomik faaliyetlerde meydana gelen gelişim ve değişime bağlı olarak zaman içinde dokuma külttüründe de değişimler görülmektedir. Yörenin birçok yerinde daha önce yapılan çöpür kilim, kilim, kolon dokuma ve mutaflık ve urgancılık gibi dokuma örneklerinin bir kısmının yok olması ya da çok az dokunuyor olmasında bu kültürel değerlere hammadde sağlayan ipekböcekçiliğinin ve pamuk gibi ekonomik faaliyetin devam ettirilmemesinin payı büyüktür. Zira yörede "şehir altı" denilen mevkiinin dut ağaçlarıyla kaplı olduğu ve cumhuriyet döneminde ipekböcekçiliği yapıldığı bilinmektedir. Yine "şehir altı" mevkii, bir dönem pamuk tarımının yapıldığı önemli bir alan olmuştur.

Yapılan alan araștırmasında, usta çırak ilişkisi içinde gelişen ve nesilden nesile aktarılan dokuma kültürünün Soruh Vadisi'ndeki; Sarıdibek, Tahtaköprü köyleri ile yörenin kuzeyindeki Özyörük Köyü'nde ve Susuz Vadisi'ndeki İncirce ve Karaahmet Mahallelerinde halen varlığını sürdürdüğü görülmüsstür.

Yöre dokumacılığında dikkat çekici diğer bir özellik ise, dokunan malzemenin türü ve şekli ile motifler gibi birçok dokuma unsurunun yöre içinde farklılık göstermesidir. Bu yapının yörenin coğrafi ve ekonomik özellikleri ile kültürel yapısının yöre içerisinde, kısa mesafede dahi farklılık arz etmesinden kaynaklandığı düşünülmektedir. Zira Soruh Vadisi'ne yerleșen Türkmen aşiretlerinin göçebe Türk kültürünün etkisi ile olsa gerek kilim heybe, çorap, kolon, başlık, çöpür kilim ve çuval dokudukları görülürken Susuz Vadisi'nde yatak çarşafi, göynek, başörtüsü, peşkir gibi dokuma ürünlerinin üretildiği tespit edilmiştir.

Vezirköprü geleneksel dokumacilığı dokuma malzemelerine göre; pamuk ipinden yapılan dokumalar (Susuz Köyü; İncirce ve Karaahmet mahalleleri), koyun yününden yapılan dokumalar (Soruh Vadisi ve Özyörük Köyü) ve keçi kılından yapılan dokumalar (mutaflık) olarak üçe ayrılmaktadır.

\subsection{Susuz Bezi Dokumacilığı}

Yapılan alan araştırmasında yöre dokuma kültürü içerisinde önemli yeri olan bez dokumacılığının geçmişte Vezirköprü yöresinin bir çok yerinde çulfalık, işlik ve düzen adı verilen dokuma tezgâhlarında hemen her evde dokunduğuna dair bilgilere ulaşılmıştır. Ancak günümüzde birçok somut olmayan kültürel miras gibi teknolojik gelişme, hammadde yetersizliği ve ilgisizlik nedeniyle gerileyen bez dokumacılığı, günümüzde sadece Susuz Vadisi'ndeki mahallelerde Susuz Bezi adıyla üretilir olmuştur.

Susuz Bezi, yörede göynek (gömlek) olarak adlandırılan iç giysiler ile sofra bezi, yatak çarşafı, başörtüsü ve peşkir gibi ürünlerinin üretiminde kullanılmaktadır. Bu ürünler aynı zamanda yörenin kendine özgü dokuma tarzını da oluşturmaktadır. Çoğunlukla kırmızı şeritlerin kullanıldığı bu dokumalar pamuk ipliği ve kökboyasından oluşmaktadır. Bugün Sarıdibek ve Tahtaköprü köylerinin kadınları halen bu başörtüsünü kullanarak bu geleneksel giyinme tarzını devam ettirmektedirler (Kıvrak, 2014, s. 467). Çıkrık yardımıyla iğlere, petek adı verilen tezgâhlarda ise makaralara sarılan pamuk ipliği "düzen", "işlik", 
"çulfalık" gibi isimler verilen basit tezgâhlarda dokunarak kültürel motiflerle süslü yöresel dokumalara dönüşmektedir. Beyaz üzerine parlak ve canlı renklerin hakim olduğu Susuz Bezi'nde; baygun, suyu, mühür, zencir, tarak dişi, süydürme, bükme ve alma kırmızısının bütünü (Foto 4) gibi yöresel isimli motiflerin kullanıldığı tespit edilmiştir. Dokuma işleminde, dolap (ip çözümünde kullanılır) petek, tarak, küçü, tufa, kuş, geledür, el ağacı, ayaklar, mekük, cimbar, argut ağacı, ip, çıkrık, kelepçe, iğ ve masura gibi 17 farklı aletten oluşan bir kombinasyon kullanılmaktadır (Foto 5-6-7).
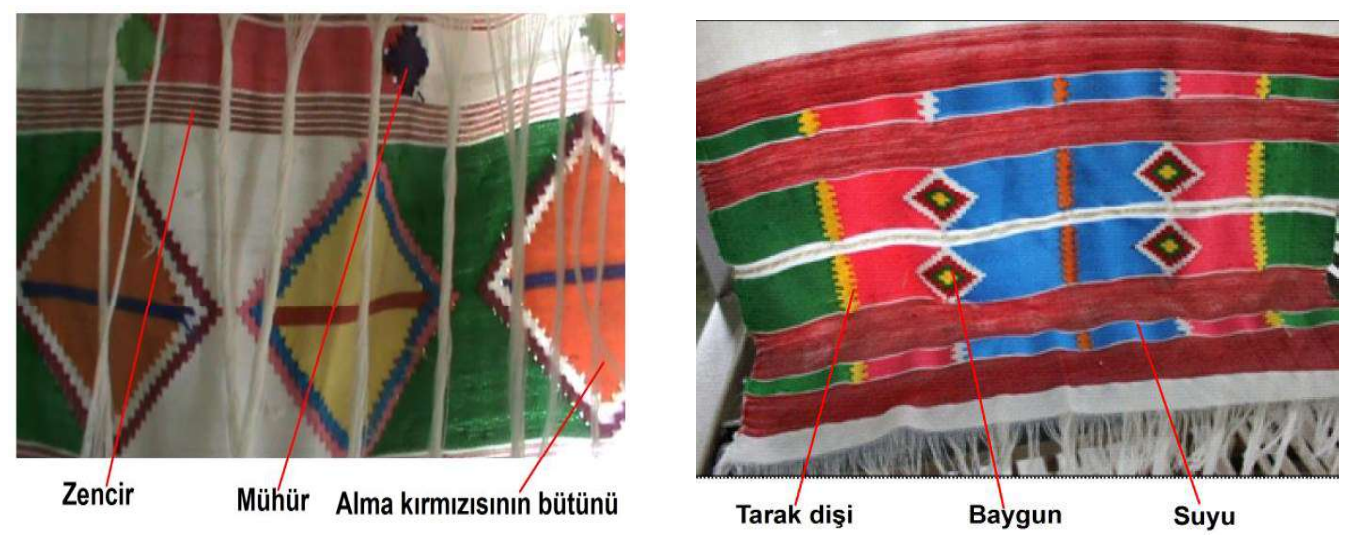

Foto 4 a-b. Susuz Bezi motif detayı ve motif isimleri (Susuz Köyü Karaahmet Mahallesi, 2014).
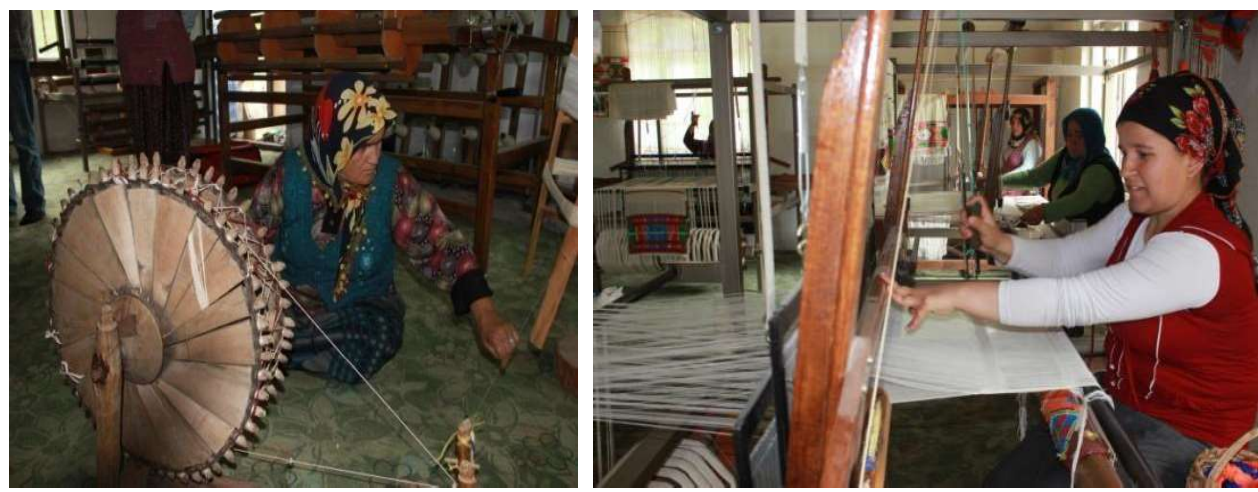

Foto 5. Susuz Köyü Karaahmet Mahallesi'nde Foto 6. Susuz Köyü Karaahmet çıkrık denilen basit makara ile iğe ip dolama işi, 2014.

Mahallesinde çulfalık ismi verilen el tezgahında Susuz Bezi dokuyan kadındalar. 



Foto 7 a-b. Susuz Vadisi'ndeki mahallelerde yapılan dokuma örnekleri (Susuz Köyü, 2014).

\subsection{Kilim, Heybe, Çorap ve Boncuklu Taç Dokumacılı̆ğ}

Soruh Vadisi'nde bulunan Sarıdibek ve Tahtaköprü köyleri ile yörenin kuzeyinde yer alan Özyörük Köyü'nde kilim, heybe, torba, çorap ve boncuklu taç dokumacılığının devam ettiği görülmüştür. Unutulmaya yüz tutmuş olsa da bahsi geçen mahallelerde bulunan tezgâhlarda ve yaylalarda geçirilen sürelerde dokuma kültürü yaşatılmaktadır. Düzen adı verilen tezgâhlarda kök boyalı koyun yününden ipliklerle dokunan kilim, heybe ve çorap dokuma örnekleri, motif bakımından oldukça zengin örnekler içermektedir (Foto 8). Vezirköprü kilimlerinde; dikine hatların arasının boynuz ve çengel motiflerini içeren tarz ve tüm Türkmen kilimlerinde görülen eli belinde, çengel, boynuz ve saç örgüsü motifleriyle bezeli iki temel motiflendirme tarzında bulunmaktadır. Bunların yanı sıra kençeli, sıçandişi, sandık nakışı gibi motiflerde halen kullanılmaktadır. Önceleri kökboyası kullanılarak renklendirilen yün ipliklerde artık sentetik boya kullanılmaktadır. Susuz Vadisi dokumalarının aksine Soruh Vadisi dokumalarında daha koyu ve mat renklerin ağır bastığı görülmüştür. Kırmızı renklerin yanında Soruh Vadisi dokumalarında çivit mavisi, siyah ve yeşil renklerin hâkim renk olarak kullanıldığı tespit edilmiştir (Kıvrak, 2014, s. 469). (Foto $9,10,11,12,13,14)$.

Soruh Vadisi'nde bulunan Tahtaköprü ve Sardibek köylerinde geçmişten günümüze devam eden kilim, heybe, boncuklu taç ve bez dokumacılığı yerel halkın kendi ihtiyaçlarını karşılamaya yönelik olup ticari bir yönü bulunmamaktadır. Ancak 2011 yılında OKA tarafından "Bir İlmek Bin Emek Projesi" kapsamında Sarıdibek ve Tahtaköprü Susuz köylerine getirilen tezgâhlarla unutulmak üzere olan bu kültürün yaşatılmasına yönelik kurslar açılmıştır. 

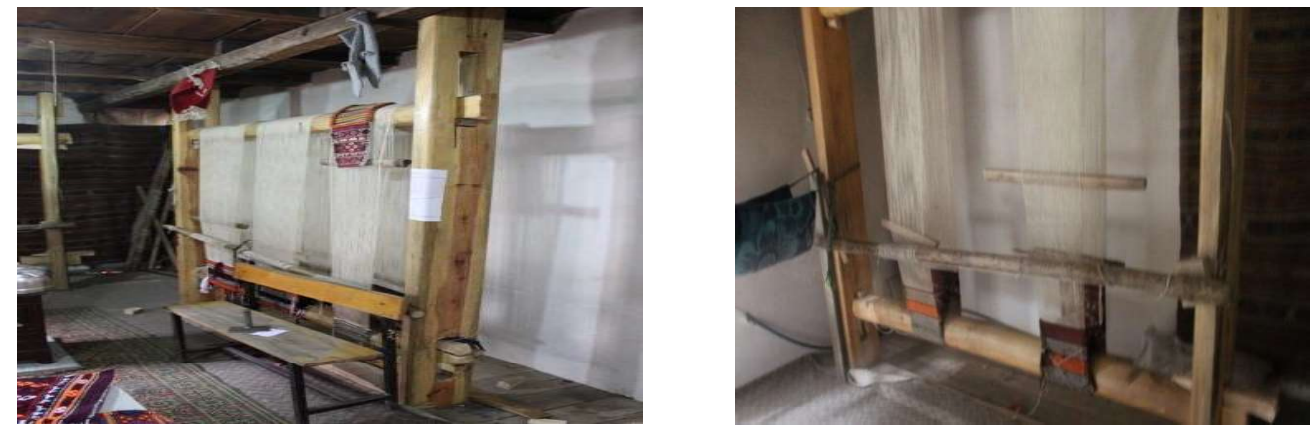

Foto 8. Soruh Vadisi'ndeki köylerde kullanılan "Düzen" adı verilen dokuma tezgahı detayı.

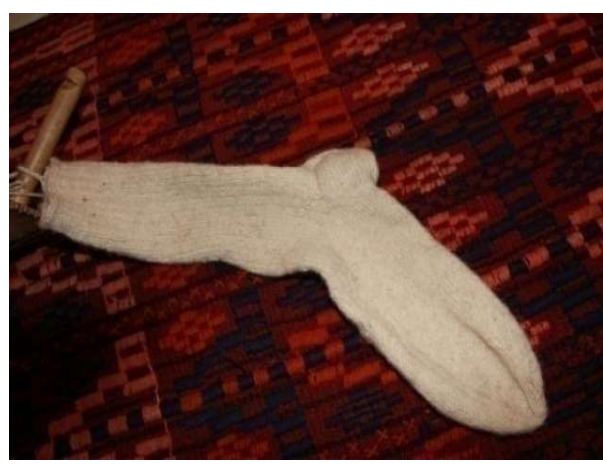

Foto 9. Tahtaköprü Köyü'nde dokunan yün çorap örneği.

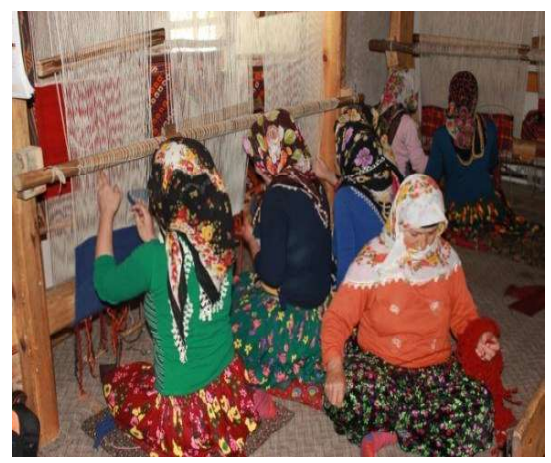

Foto 11. Tahtaköprü Köyü'nde düzen adı verilen el tezgâhında kilim ve heybe dokuyan kadınlar.



Foto 10. Tahtaköprü Köyü'nde Kadınların çocuklarının sırtlarına bağladıkları kuşak örneği

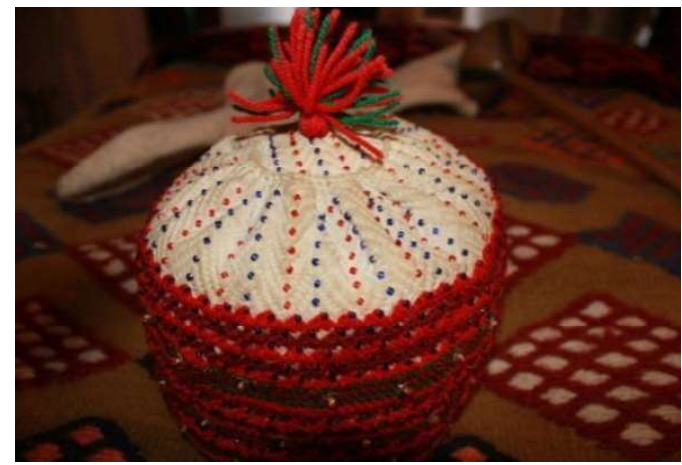

Foto 12. Tahtaköprü Köyü'nde dokunan boncuklu taç örneği. 


\subsection{Kıl Kilim (Çöpür) ve Çuval Dokumacılı̆̆ı}

Yörede görülen diğer bir dokuma türü ise keçi kılından dokunan çöpür (kıl kilim) ve çuvaldır. Keçi kılından hayvan çulu, yem torbası gibi şeyler dokuyan kimse mutaf, bu dokumacılık türü ise mutaf dokumacılığı olarak tanımlanmaktadır. Mutaflık, yıllarca geniş ormanlara sahip ve kıl keçisi yetiştiriciliğine uygun Vezirköprü için vazgeçilmez mesleklerden biri olmuştur. Göçebe Türk kültüründe önemli bir yeri olan çadır ve çadırı oluşturan kıl dokumalar, özellikle Yörük kültürünün yaşatılmaya çalışıldığı Aydınlı, Özyörük, Tahtaköprü, Sarıdibek ve Türkmen köylerinde unutulmaya yüz tutmuş olsa da varlığını korumaktadır. Keçi kılının doğal renkleri ile boya kullanılmadan siyah zemin üzerine beyaz yolların kullanıldığı çöpür kilimler ile göç esnasında çadırların ve çeşitli malzemelerin içine konulduğu kıl çuvallar yöredeki dokuma kültürünün diğer elemanlarıdır. Vezirköprü'de bugün bile Mutaflar Çarşısı (Foto 15) olarak anılan bir sokağın varlığı bunu desteklemektedir. Kırsal bölgelerden satın alınan keçi kılı, Vezirköprü'de bulunan Taşhan ve Üzüm hanı gibi hanlarda eğirilip ip haline getirilerek, yıllarca Mutaflar çarşısındaki işyerlerinde hayvan çulu, yem torbası, çöpür kilim, çadır, heybe ve çuval gibi şeylerin dokumasında kullanılmıştır (Kıvrak, 2014, s. 469).



Foto 13. Tahtaköprü Köyü'nde dokunan kilim örneği.

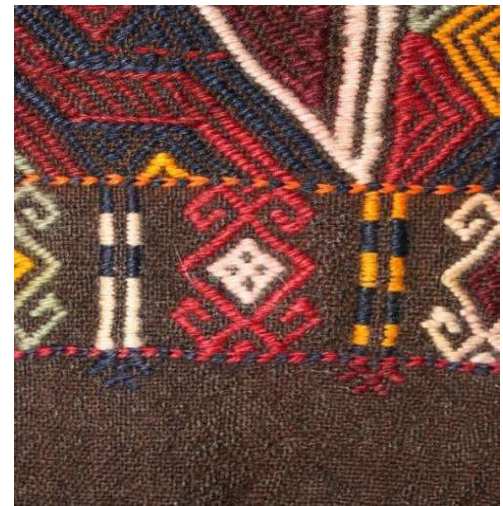

Foto 14. Özyörük Köyü'nde dokunan. kilim örneği

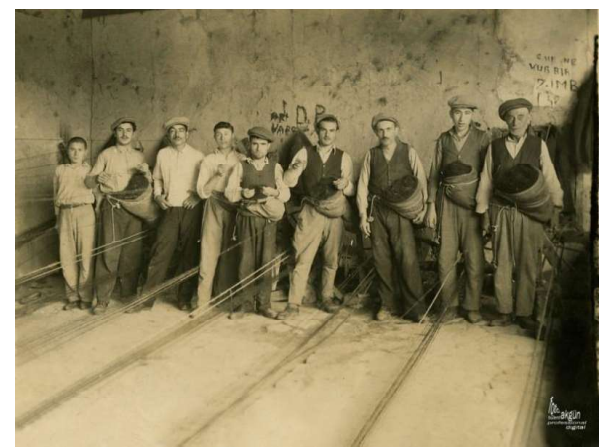

Foto 15. Vezirköprü Taşhan'da Mutaflar (M. Cebeci Arşivi). 


\section{Sonuc ve Öneriler}

Dokumacılık, bütün el sanatlarında olduğu gibi Anadolu'da ve Vezirköprü’de yüz yıllardır varlığını koruyan kültürel bir mirastır. Dokumaların Türk ve dünya külttür tarihi açısından önemli bir yeri vardır. Bu somut olmayan kültürel mirasın ortaya çıkışı ve gelişimi ise büyük ölçüde kültürrel bir birikimin eseridir (Atasoy, 2014). Kültür coğrafyası açısından incelenmeye çalışılan Vezirköprü yöresi dokuma kültürünün gelişimi de büyük ölçüde yörenin yerleşme ve dokuma tarihi ile bağlantılıdır. Yapılan yüzey araştırmalarda Vezirköprü ilçe merkezine çok yakın olan Adatepe'de Kalkolitik Döneme yani günümüzden 7500 yıl öncesine ait izlere rastlanmıştır (Oymaağaç-Nerik, 2011, s. 43). Sirasıyla Hitit Uygarlı̆̆ı, Frig, Pers, Roma, Bizans egemenliğinde kalan yöre 1071'de Türklerin Anadolu'ya girişleri ve Türkmen aşiretlerinin Bizans sınır hatlarında beylikler kurmasıyla Türklerin eline geçmiştir. 1160 yılında Anadolu Selçuklu Devleti Sultanı Mesud'un, şehri Danişment'lilerden almasıyla Gedagra (Büyükkale) olarak isimlendirilen yöre, Yörgüç Paşa'nın Canik Seferi (1426-1427) sırasında Osmanlı sınırlarına dahil edilmiş "Köprü" ismini almıştır. Sayılan dönemlerin hemen hepsinde yörede dokuma kültünün varlığına ait emareler (ağırşak, iğ, makaralar) tespit edilmiştir. Türklerin yöreye yerleşmeleriyle Türk dokuma kültürü yöreye hâkim olmaya başlamıştır. Günümüzde ise yörenin dokuma kültürü ürünlerinde ve bu ürünlerdeki desenlerde Türk kültürünün etkisi görülmektedir.

İnsanın yaşam alanı olarak seçtiği yerlerin farklılığı yaşama biçimine, kültürüne doğrudan yansımaktadır (Emekli, 2006, s. 51-59). Vezirköprü yöresi; Susuz Bezi, kilim, heybe, çorap, boncuklu taç ve bez bebek, kıl kilim (çöpür) ve çuval dokumacıllğı gibi dokuma kültürüne ait değerleriyle önemli bir potansiyele sahiptir. Vezirköprü yöresinde dokuma kültürünün gelişiminde ve geçmişten günümüze devam etmesinde, dokuma külttürüne ait kültürel değerlerde ve onların mekâna dağılışında yörenin coğrafi çevre özelliklerinin etkisi görülmektedir. Yörenin iklim ve toprak özellikleri dokuma kültürüne hammadde oluşturan tarım ürünlerinin yetiştirilmesini desteklemiştir. Yöre Demir Çağı'nda keten, Osmanlı ve Cumhuriyet Döneminde ise pamuk ve ipekböcekçiliğinin yapıldığı bir alan olmuştur. Bu tarımsal üretim ise tarih boyunca dokuma kültürünün sürdürülebilirliği üzerinde önemli bir faktör olmuștur.

Kültürler ilişkisiz özellikler dizisi olmaktan çok, karmaşık bütünler; tüm parçalarının nedensel olarak birbirine uyduğu bütünleşmiş birimlerdir. Kültürel değerler her yönüyle mekânsal bakımdan coğrafi çevre bileşenleriyle bağlantılı ve bütünleşmiştir (Tümertekin ve Özgüç, 2009, s. 96). Yani, bir kültür ürününün mekânsal dağıllışını ve mekânsal çeşitliğini çevre, kültürr ve dağglış ilişkileri açından incelemeden anlamak olanaksızdır. Vezirköprü yöresinde dokuma kültürü yöre içerisine dağılmış olmakla birlikte; Soruh Vadisi, Susuz ve Özyörük mahalleleri bu kültürün yoğunlaştı̆̆ mekânlardır. Dokuma kültürünün bu alanlara dağılmasında ve devam ettirilmesinde; Türkmenlerin yoğun olarak bu alanlara iskân etmesi, bu alanlarda yapılan ekonomik faaliyetin türü (yoğun olarak hayvancılık), bu alanların engebeli bir topografyaya sahip olması ve şehir merkezine uzaklığı ve ulaşımın zor olması nedeni ile kültürel değişimin daha yavaş olmasının etkili olduğu düşünülmektedir.

Oymaağaç-Nerik kazısı ve yüzey araştırmalarından elde edilen bulgular tarihi dönemler boyunca dokumacıllğın yöre ekonomisinde önemli bir yerinin olduğunu göstermektedir. Vezirköprü yöresi 19. yüzyılın başlarında birçok dokuma ürünü (muslin, maroken, şal, şilte) ve dokumacılıkta kullanılan (çivit ve kökboyası gibi) pamuk, yün ve boyaların ulusal ve uluslararası düzeyde ticaretinin yapıldığı bir yer konumunda olmuştur. 
İhtiyaçtan çok ticari bir faaliyet olarak yapılan dokumacılık bu dönemde yöre ekonomisi için önemli ekonomik faaliyetlerden biri olmuştur.

Vezirköprü yöresinde hem doğal çevrenin etkisi hem de tarihi birikimle oluşan dokuma kültürüne ait değerlerin gelişimi, korunması ve sürdürülebilirliği için yörenin mevcut dokuma kültürü potansiyeline dair iyi bir alan araştırmasıyla desteklenen el sanatları envanterine ihtiyaç bulunmaktadır. Öncelikli olarak yerel yönetim, kamu ve diğer paydaşların bir araya gelerek UNESCO'nun Somut Olmayan Kültürel Miras Sözleşmesi'ndeki hedeflerine uygun olarak yörenin dokuma kültürünün geleceğine dair faaliyet planı hazırlanmalıdır. Bu plan kısa vadeli (taktik planlama) ve uzun vadeli (stratejik planlama) olarak iki şekilde olmalıdır. Kısa vadeli planlamada, hâlihazırda yörenin dokuma kültürünün önemli değerleri olan Susuz Bezi, Soruh Vadisi kilim, heybe, çorap ve boncuklu taç dokumacıllğının tanıtımı ve üretilen ürünlerin pazarlanması noktasındaki sorunlar çözülmelidir. Kırsal kesimde el sanatlarının üretilmesi konusunda yaşanan diğer sorun ise hammaddedir. Özellikle kökboyası kullanılarak üretilen ve kilim ve bez dokumacılığında kullanılan yün iplikler, artık yörede üretilmemektedir. Vezirköprü'de Samsun Büyükşehir Belediyesi tarafindan bir tesis kurularak burada kökboyalı iplik üretimi yapılmalıdır. Bu tesiste üretilen iplikler Vezirköprü yöresinde kilim ve bez dokumacılığı önündeki hammadde sorunu çözüleceği gibi diğer ilçelere hatta diğer şehirlere de pazarlanarak ekonomik girdi elde edilebilecektir.

Ulusal ve uluslararası turizm verilerine göre turistlerin en fazla harcama yaptıkları kalemler arasında halı, kilim ve hediyelik eşyalar gelmektedir (Gül ve Yılmaz, 2016, s. 4647). Günümüzde yöre dokuma kültürü açısından zengin sayılabilecek ürün çeşitliliğine sahip olmasına rağmen bu ürünler, yerel ekonomiye katma değer sağlama noktasında henüz istenilen düzeyde değildir. Bu nedenle uzun vadeli planlama ile yörenin dokuma kültüründe varlıkları bilinen kıl kilim (çöpür), mutaf ve çuval dokumacılığı gibi değerlere yönelik; usta yetiştirme ve hammadde sağlamaya yönelik tarımsal üretimi (keten, ipek böceği, pamuk, kenevir, kıl keçisi) destekleme ve bu değerleri yöre ekonomisine katma değer sağlayacak turistik ürünlere dönüştürme gibi konuları içine almalıdır. Özellikle Soruh Vadisi kilimleri ve Susuz Bezi dokumalarından laptop çantası, el çantaları, hediyelik paket çantaları, süs eşyaları, cep telefonu kılıfları gibi küçük hediyelik eşyalar üretilerek turistlere sunulmalıdır. $\mathrm{Bu}$ ürünlerin gerek Vezirköprü ilçe merkezinde gerekse Samsun il merkezinde Belediye tarafından oluşturulacak reyonlarda tanıtım ve pazarlanması sağlanmalıdır. Ayrıca Vezirköprü yöresini sembolize eden önemli kültür unsurlarından Susuz Bezi ve Soruh Vadisi kilimlerinin coğrafi işaretlemelerinin yapılmasına ve markalaşmasına yönelik yerel yönetim ve diğer paydaşların gerekli işlemleri başlatmada acele edilmesi gerektiği düşünülmektedir.

\section{KAYNAKÇA}

ATASOY, F. (2014). İpek Yolunda Türk Dünyası Ortak Kültür Mirast. Ankara: Türk Yurdu Yayınları.

AYGÜN, N. (2009). Osmanlı Devleti'nin Son Zamanlarında Karadeniz'in Güney Kesiminde İktisadî Faaliyetler. Karadeniz Araştırmalar , 41-76.

AYTAÇ, A. (2008). Türk Medeniyetinde Dokuma Kültürü Ve Yabancı Resim Sanatı Üzerindeki Tarihsel Yeri. 38. ICANAS (S. 203-220). Ankara: Atatürk Kültür, Dil Ve Tarih Yüksek Kurumu YayınlarıEMEKLİ, G. (2006). Coğrafya, kültür ve turizm: kültürel turizm. Ege Coğrafya Dergisi, 15, 51-59. 

Neșriyat.

ÇELEBİ Evliya (1986). Tam metin seyahatname. (Cilt 2-3). İstanbul: Üçdal

FOURCADE, P. (1806). Ville et territoire de VezirKioprou, . Paris: AMAE.

GÜL, S. ve YILMAZ, A. (2015). Vezirköprü'de (Samsun) tarihsel koruma ve halkın koruma çalışmalarına yaklaşımı. Studies of The Ottoman Domain, 5 (8), 1-28.

GÜL, S. ve YILMAZ, A. (2016). Vezirköprü yöresi kültür turizmi potansiyelinin analitik hiyerarşi yöntemi ile belirlenmesi ve SWOT ölçütlerinin temel kültür turizmi kriterleriyle olan ilişkisi. Studies Of The Ottoman Domain, 6, (11), 43-63.

KARABAŞA, S. (2013). Ekolojizmin ortak paydasında geleneksel el sanatları, yeşil tekstil ve yavaş moda (Sultan Sazlığı örneği). Akdeniz Sanat Dergisi, 4 (8).

KIVRAK, B. (2014). Vezirköprü'de el sanatları. Vezirköprü Araştırmaları, (s. 457467). Samsun: Erol Ofset.

OĞUZ, M. Ö. (2002). Küreselleşme ve ulusal kalıt kavramları arasında Türk halkbilimi. Millî Folklor, 50, 5-8.

OMUR, O. (1997). Anadolu el sanatlarının çağdaş sanat içindeki yeri. $V$. Milletlerarası Türk Halk Kültürü Kongresi Maddi Kültür Seksiyon Bildirileri, (s.471-478). Ankara: Kültür Bakanlığı Yayınları Oymaağaç Höyük - Nerik (2011). Ylllık rapor. Erişim tarihi: 10 Eylül 2014, http://www.nerik.de/oezet/onlineyayinlari.php?artikelid=149

ŞEMSETTIN S. (1896). Kamus-ül A'lâm: Köprü. Vezirköprü Araştırmaları (s. 75 79). Samsun: Erol Ofset.

TDK (2018). Çivit. Erișim tarihi:20.02.2018.

http://www.tdk.gov.tr/index.php?option=com_ttas\&view=ttas\&kategori1=derlay\&k elime1 $=\%$ C3\%A7ivit

TDK (2018). Maroken. Erişim tarihi: 20.02.2018. , 2018,

http://www.tdk.gov.tr/index.php?option=com gts\&kelime $=\%$ C4\%B0SKEMLETDK

TDK (2018). Muslin. Erişim tarihi:20.02.2018.

http://www.tdk.gov.tr/index.php?option=com_gts\&arama=gts\&guid=TDK.GTS.5ab 640c512e3f2.07207046

http://www.oed.com/view/Entry/124185,

TDK (2018). Şilte. Erişim tarihi: 20.02.2018.

http://www.tdk.gov.tr/index.php?option=com_gts\&kelime $=\% \mathrm{C} 5 \% 9 \mathrm{E} \% \mathrm{C} 4 \% \mathrm{~B} 0 \mathrm{LTE}$

TÜMERTEKIN, E. ve ÖZGÜÇ, N. (2009). Beşeri Coğrafya: İnsan. Kültür. Mekan. İstanbul: Çantay Kitabevi.

YILMAZ Ö. (2015). Sinop Fransız konsolosu Pascal Fourcade'ın 1806 yılı Amasya, Lâdik ve Vezirköprü seyahatleri. III. Uluslararası Geçmişten Günümüze Merzifon ve Amasya Yöresi Sempozyumu, (s.155). Ankara: Edge Akademi Yayınevi. 